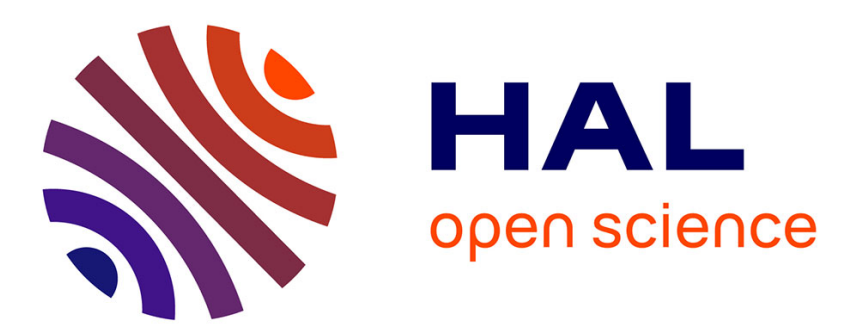

\title{
Left premotor cortex and allophonic speech perception in dyslexia: a PET study.
}

O. Dufor, W. Serniclaes, L. Sprenger-Charolles, Jean-François Démonet

\section{To cite this version:}

O. Dufor, W. Serniclaes, L. Sprenger-Charolles, Jean-François Démonet. Left premotor cortex and allophonic speech perception in dyslexia: a PET study.. NeuroImage, 2009, 46 (1), pp.241-8. 10.1016/j.neuroimage.2009.01.035 . hal-00733531v2

\section{HAL Id: hal-00733531 \\ https://hal.science/hal-00733531v2}

Submitted on 24 Sep 2012

HAL is a multi-disciplinary open access archive for the deposit and dissemination of scientific research documents, whether they are published or not. The documents may come from teaching and research institutions in France or abroad, or from public or private research centers.
L'archive ouverte pluridisciplinaire HAL, est destinée au dépôt et à la diffusion de documents scientifiques de niveau recherche, publiés ou non, émanant des établissements d'enseignement et de recherche français ou étrangers, des laboratoires publics ou privés. 


\section{Accepted Manuscript}

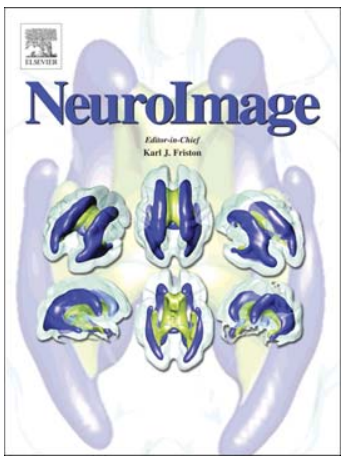

PII:

S1053-8119(09)00081-0

Left premotor cortex and allophonic speech perception in dyslexia: A PET study.

O. Dufor, W. Serniclaes, L. Sprenger-Charolles, J.-F. Démonet

DOI:

doi: 10.1016/j.neuroimage.2009.01.035

Reference: $\quad$ YNIMG 5962

To appear in: $\quad$ NeuroImage

Received date: 16 July 2008

Revised date: $\quad 7$ January 2009

Accepted date: $\quad 22$ January 2009

Please cite this article as: Dufor, O., Serniclaes, W., Sprenger-Charolles, L., Démonet, J.-F., Left premotor cortex and allophonic speech perception in dyslexia: A PET study., NeuroImage (2009), doi:10.1016/j.neuroimage.2009.01.035

This is a PDF file of an unedited manuscript that has been accepted for publication. As a service to our customers we are providing this early version of the manuscript. The manuscript will undergo copyediting, typesetting, and review of the resulting proof before it is published in its final form. Please note that during the production process errors may be discovered which could affect the content, and all legal disclaimers that apply to the journal pertain. 
Left premotor cortex and allophonic speech perception in dyslexia: a PET study.

Premotor cortex and speech perception in dyslexia. (running head) O. Dufor ${ }^{\mathrm{a}}$, W. Serniclaes ${ }^{\mathrm{b}}$, L. Sprenger-Charolles ${ }^{\mathrm{b}}$, J.-F. Démonet $^{\mathrm{a}}$

aINSERM, Unit 825, Laboratoire Imagerie cérébrale et handicaps neurologiques, CHU Purpan, Department of Neurology, Toulouse, F-31059, France; Université Toulouse III Paul Sabatier, Toulouse, F-31000, France.

bCNRS, UMR 8158, Laboratoire Psychologie de la Perception, Paris F-75270, France;

Université Paris Descartes, Paris F-75270, France.

\section{Contact : olivier.dufor@inserm.fr}

Address for manuscript correspondence : $\quad$ Tel : 33 (0) 561779519

Fax : $33(0) 561499524$

E-mail : olivier.dufor@inserm.fr 


\section{Abstract}

Disorders of categorical perception has been put forward as a new account of phonological deficit in dyslexia (Serniclaes et al., 2001) so that dyslexic subjects tend to discriminate phoneme instances within a given phonemic category rather than between categories, possibly witnessing the persistence of phonemic boundaries of 'allophones' that may be relevant to other languages although not to one's mother tongue (Serniclaes et al., 2004). The brain correlates of within- and between-category discrimination were explored using a /ba/-/da/ phonetic continuum and $\mathrm{H}_{2}{ }^{15} \mathrm{O}$ PET in 14 dyslexic and 16 control adult readers; subjects discriminated a set of stimuli pairs, first in a 'naïve' (acoustic) condition and, after debriefing about the stimuli identity, in a speech (phonemic) condition (Dufor et al., 2007). While discrimination of 'between' pairs improved in all subjects following debriefing, 'within' stimuli yielded variable performance; some subjects kept discriminating them, while best categorizers judged them identical. Correlation analyses between acoustic-to-speech changes in brain activity and in 'within'-pair discrimination, and between control and dyslexic groups, revealed a criss-crossed correlation pattern in the left BA6 so that the higher the activity the better the categorization in control subjects whereas the higher the activity the more increased 'within' discrimination in dyslexic subjects. Therefore, in average readers, enhanced activity in the left BA6 likely contributes to optimizing phoneme categorization via refined speech motor coding. In dyslexic subjects showing sensitivity to 'within'-category cues, activity enhancement in this region might suggest the persistence of motor coding for allophonic representations of speech.

\footnotetext{
Abbreviations : $\mathrm{CP}=$ categorical perception; $\mathrm{AC}=$ acoustic $; \mathrm{SP}=$ speech (phonemic) $; \mathrm{PET}=$ positon emission tomography; $\mathrm{CBF} / \mathrm{rCBF}=$ cerebral blood flow / regionalCBF; $\mathrm{IFG}=$ inferior frontal gyrus ; $\mathrm{STG}=$ superior temporal gyrus ; $\mathrm{MTG}=$ middle temporal gyrus ; $\mathrm{IPL}=$ inferior parietal lobule ; $\mathrm{SMG}=$ supra-marginal gyrus $; \mathrm{AG}=$ angular gyrus $; \mathrm{BA}=$ Brodmann area.
} 


\section{Introduction}

Among the various possible causes of developmental dyslexia (Demonet et al., 2004), phonological disorders have primary importance (Ramus et al., 2003) and recent research suggests a new explanation of phonological deficit in dyslexic subjects (see for a review Sprenger-Charolles, 2006). In this paper we consider only two hypotheses relating to speech perception impairment. The "temporal processing hypothesis" supposes that dyslexia is caused by a basic sensory deficit of brief acoustic cues discrimination (Tallal and Piercy, 1973). The phonological hypothesis relates reading/writing deficits to ill-formed phonological representations or processing (see for a review, Rosen, 2003). The former hypothesis is usually thought of as a component of a largest theory that brings together other sensory deficits implicating the magnocellular pathways (Stein and Walsh, 1997). However this account based on low-level perceptual deficits cannot explained deficits observed in dyslexia that occurs only in linguistic contexts (Serniclaes et al., 2001). Furthermore it has been suggested that disorders of temporal processing in speech signal concern only subgroups of readers with dyslexia (Giraud et al., 2005). Using PET brain imaging and an auditory discrimination task, we showed in control readers activations in the left temporal and parietal cortices when participants categorized stimuli as speech samples. In adults with dyslexia these regions were significantly less activated (Dufor et al., 2007) and these results lend further support to a deficit of activation of the neural network related to phonological processing in dyslexia (Ruff et al., 2002). In the present paper we performed further analyses of the data used in (Dufor et al., 2007) to explore complementary effects relating to categorical perception of speech. Correlations across subjects in the groups of control and dyslexic readers were studied between changes in PET activation signal and performance on categorical perception from the naïve stage of the experiment in which subjects processed stimuli as non-speech acoustic stimuli to the debriefed stage in .which subjects were aware that these very same stimuli were in fact syllables. 
Based on previous results,(Serniclaes et al., 2004) we assumed that speech perception of some of our subjects with dyslexia involved 'allophonic' units rather than phonological categories. Allophones correspond to contextual variants of phonemes in the language of interest while being potentially phonemic in other languages. For instance the prolongation of vowel duration (e.g. / i / vs / i: /) is only a prosodic variant in French while it yields discrimination between two distinct phonemes in other languages such as English (e.g. /ship/ versus /sheep/). A linguistically irrelevant sensitivity to allophones has straightforward deleterious consequences for relating speech sounds to visual symbols in alphabetic writing systems. As several allophones may exist for a single phoneme, one-to-one correspondences between speech sounds and letters is not possible even if the orthographic system is strictly based on one-to-one correspondences between phonemes and letters (i.e. if the orthographic system is perfectly transparent).

The rationale for postulating an allophonic mode of speech perception in children with dyslexia aroused from studies of Categorical Perception. Categorical Perception (CP) means that only differences between phoneme categories (e.g. /b/ versus /d/) can be distinguished, not the within-category variants (Liberman et al., 1957) (e.g. different instances of /b/) . Dyslexic subjects have been shown to suffer from a deficit in CP of speech sounds in a fairly large number of studies starting with Brandt and Rosen (Brandt and Rosen, 1980). However, the interest of the $\mathrm{CP}$ deficit was reinforced by findings from some of us showing that a group of teenager dyslexic subjects not only have weaker discrimination between categories but also better discrimination within categories (Serniclaes et al., 2001), thereby differing from other perceptual deficits which all point to reduced sensory capacities. Instead of being a matter of weakened resolution, the $\mathrm{CP}$ deficit might therefore be linked to over-discrimination of stimulus differences which are not functional for linguistic purposes. Further, Serniclaes and colleagues (Serniclaes et al., 2004) showed that the over discrimination of within-category 
differences by dyslexic children was not due to an overall higher sensitivity to acoustic details but rather to a higher sensitivity to allophonic differences between speech sounds. This was recently confirmed in Bogliotti and colleagues study (Bogliotti et al., 2008) for comparisons between dyslexic children and chronological age controls but also for comparisons between dyslexic readers and reading age level controls.

As transient acoustic events, stop consonants might be more difficult to discriminate than vowels for subjects with dyslexia depending on the severity of the disorder (Giraud et al., 2008) Asymmetry of voice onset time-processing in adult developmental dyslexics. Good examples of allophonic perception could be derived from consonants which differ according to stop place of articulation. In English and French, only three different stop place of articulation are phonemic and they give rise to the $\mathrm{b} / \mathrm{d} / \mathrm{g}$ and $\mathrm{p} / \mathrm{t} / \mathrm{k}$ distinctions, for the voiced and voiceless consonants respectively. However, many other places of articulation are possible. For instance, the French /d/ is split into two different phonemes in Hungarian, a language with four places of articulation categories (Serniclaes and Geng, accepted). The /d/ variants are allophones in French and similar allophonic variants should also exist for the /b/ and /g/ phonemes given the large number of possible places of articulation across languages. Sensitivity to such allophonic distinctions can readily explain the over-discrimination of within-category differences by young dyslexic subjects on, for instance, a ba/da stimulus continuum as $/ \mathrm{da} /$ covers different allophonic regions in the perceptual space. Whereas the above-mentioned behavioural studies dealt with children, our studies concern adult dyslexic and healthy groups (Dufor et al., 2007) in which we addressed CP using both behavioural and neuroimaging approaches. Three types of pairs were used, pairs involving either physically identical stimuli (SAME pair), or acoustically different but within the same phoneme category (/ba/ or /da/ WITHIN pairs), or different and taken from the two different categories (ba/da BETWEEN pairs). The experiment involved learning to discriminate auditory synthetic 
stimuli and was two-fold. First, subjects were not informed that the synthetic stimuli corresponded to syllables $/ \mathrm{ba} /$ and $/ \mathrm{da} /$. This was the 'acoustic' condition. Then the subjects were debriefed and trained to distinguish types of pairs according to their specific phonological properties. This was the 'speech' condition.

Top-down effects resulting from debriefing and training on the same set of stimuli between the acoustic and speech condition induced enhanced activities in a typically language-related left-sided premotor, superior temporal and inferior parietal network in control readers. A number of studies in adults (Liebenthal et al., 2005, Desai et al., 2008), had already demonstrated the involvement of the latter two areas in phoneme perception. Overall, these studies revealed an implication of the left superior temporal sulcus and the left superior marginal gyrus although not addressing top-down effects that could only be analyzed by using physically identical stimuli in naïve (acoustic) and debriefed (speech) conditions. By doing so, we showed that this enhancement of activity between the acoustic and the speech condition was significantly altered and less left-lateralized in dyslexic subjects relative to control readers. However, in the speech condition, the behavioural effects were similar in both groups, showing massive improvement of discrimination for BETWEEN pairs while fewer changes were seen for WITHIN and SAME pairs. Therefore the 'allophonic', within-category effect reported in younger dyslexic subjects (Serniclaes et al., 2001, Serniclaes et al., 2004, Bogliotti et al., 2008) was not observed in our study (Dufor et al., 2007). Yet, a closer analysis revealed large across-subject variability so that some subjects tended to show this within-category effect while others demonstrated CP.

In their experiment, S.E. Blumstein et al., (Blumstein et al., 2005), showed cortical areas implicated in processing the phonetic structure (voice onset time) of category $(/ \mathrm{t} / \mathrm{versus} / \mathrm{d} /$ ); they observed that some regions, including the left inferior frontal gyrus and a part of the anterior cingulate cortex, were more engaged in identifying "within" stimuli than "endpoint" 
stimuli along a /da/-/ta/ continuum. The authors concluded that the measured activities were modulated "as a function of graded category membership (boundary $>$ withincategory>endpoint)", whereas other regions in the temporo-parietal cortex including STG, MTG, IPL and AG would support the "function of best fit to the phonetic category".

In the present paper we examined responses to 'WITHIN' pairs to further appraise categorical perception across subjects in each group. Even though on average all subjects tended to respond "different" to "BETWEEN" after debriefing, only the "best categorizers', i.e. subjects showing the best pattern of $\mathrm{CP}$, would also be prone to respond more frequently 'identical' to "WITHIN" pairs; conversely, subjects showing a trend to allophonic perception would have the reverse behaviour, i.e. discriminating items in WITHIN pairs in spite of debriefing. We addressed how brain regions activity would correlate with the distribution of subject's performance ranging from $\mathrm{CP}$ to allophonic perception. To reach this aim, we therefore studied, in each group of subjects, the correlation between changes in cerebral blood flow signal and WITHIN pairs discrimination performance across acoustic and speech conditions.

Based on the literature and recent studies, (Blumstein et al., 2005, Hutchison et al., 2008), we hypothesized that correlation results would show that 'best categorizers' in the healthy group exhibited enhanced signals in the above-mentioned left inferior and lateral premotor cortex and the anterior cingulate cortex (Price et al., 1994, Wise et al., 1999, Ruff et al., 2002, Ruff et al., 2003) (see for a review Demonet et al., 2005b). Relying on results of our previous study (see Dufor et al., 2007, p.1702, figure 7A) we expected dyslexic subjects to differ significantly from control subjects for this correlation pattern in this region.

\section{Method}


Participants. We studied thirty French-speaking individuals, fourteen men (mean age $30 \pm 9.8$ years) showing typical sequelae of developmental dyslexia and sixteen healthy men (mean age $27.6 \pm 5.1$ years). Individual with dyslexia were diagnosed in accordance with the guidelines of the WHO ICD-10 and had a documented antecedents of reading difficulties during childhood and received speech remediation over variable periods. Participants were asked to fill in a systematic questionnaire including an estimation of the duration of speech therapy $($ mean $=2.87$ years, $\min =1$ month, $\max =11$ years $)$. All participants were free of neurological or psychiatric disease or hearing impairment (tonal audiometry). All participants had normal performance IQ (score $>90$ on Wechsler Adult Intelligence Scale, WAIS III) and achieved a high school level. Four dyslexic subjects and three control subjects were lefthanded according to the Edinburgh Inventory (Oldfield, 1971).

Language and working memory were assessed using the following tests : reading of regular, irregular and "loan" words (e.g., "fuel" in French), rapid digit naming, phoneme awareness tasks (notably first-phoneme subtraction, rhyme judgment, oddity judgement, i.e., detection of the odd word among 4 words, and spoonerisms) and auditory word span for 1- syllable and 4syllable words (Table 1 and Table 2 in Dufor et al., 2007). In accordance with a previously established procedure, four behavioural tests were used to further ascertained the diagnosis of developmental dyslexia: reading regular words (cut-off latency between stimulus appearance on a computer screen and onset of subject's oral response $660 \mathrm{~ms}$ ), reading legal pseudowords (cut-off latency $940 \mathrm{~ms}$ ), reading aloud 50 digits (mean time cut-off $18 \mathrm{~s}$ ), spelling on dictation of 15 irregular frequent words (cut-off $>3$ errors), (see Table 1 in Dufor et al., 2007). Cut-off score was defined following a pre-experimental study involving a separate group of 18 adult dyslexic subjects and 65 control subjects; these criteria are those used in the European Dyslexia Study, as described by Paulesu (Paulesu et al., 2001) and were also used 
by Ruff (Ruff et al., 2002, Ruff et al., 2003), by Silani (Silani et al., 2005) and by Pernet (Pernet, 2008). Subjects were considered dyslexic when they scored out of cut-off in at least two of the four tests.

Subjects involved in the average reader group did not match any of the items of the systematic inventory of dyslexia. They did not present any history of learning disabilities in childhood and scored in the normal range on the above listed tests used to diagnose dyslexia. In addition, the " $\mathrm{d} 2$ " test, a visual test for sustained attention (Brickenkamp, 1994) was used to exclude subjects presenting a developmental disorder of attention; only subjects scoring on the GZ index in the upper two quartiles were included.

The study was approved by the local Ethics committee and all subjects gave written informed consent.

PET scanning: subjects were scanned in the same condition as those described in our previous work, i.e. in a darkened room with their eyes closed and their head immobilized and aligned transaxially to the orbitomeatal line with a laser beam. Measurements of regional distribution of radioactivity were performed with an ECAT HR $+\left(\right.$ Siemens $\left.^{\circledR}\right)$ PET camera with full volume acquisition (63 planes, thickness $2.4 \mathrm{~mm}$, axial field-of-view $158 \mathrm{~mm}$, in-plane resolution $\mathrm{N} 4.2 \mathrm{~mm}$ ). The duration of each scan was $80 \mathrm{~s}$; about $6 \mathrm{mCi}$ of $\mathrm{H}_{2}{ }^{15} \mathrm{O}$ was administered to each subject. Stimulation on the experimental conditions was started 20s before data acquisition and continued until scan completion.

MRI scanning. For accurate anatomical localization of activated foci, all subjects were scanned at the Neuroradiology Department of Toulouse Purpan hospital on a Siemens Magnetom Vision (1.5 Tesla). After sagittal localization images, a 3D high-resolution T1- 
weighted data set of the whole brain was performed parallel to the intercommissural plane on every participants $\left(172\right.$ slices, matrix $=256 \times 256$, voxel size $\left.=1.17 \mathrm{~mm}^{3}\right)$.

Data recording. The Presentation ${ }^{\circledR}$ software was used to deliver digitized stimuli and to record response accuracy and reaction time. All functional PET images obtained were processed with Matlab 6.5 (Mat-Works, Natick, MA, USA) and the Statistical Parametric Mapping software (SPM2, Wellcome Department of Imaging Neuroscience, London, UK, 2002, www.fil.ion.ucl.ac.uk).

Stimuli and paradigm. Sinewave analogues of a (consonant+vowel /a/) syllables were used wherein the consonant was varied along a place-of-articulation continuum from $/ \mathrm{b} /$ to $/ \mathrm{d} /$. Appropriate values were set so that a phonetic continuum yielded perception of a $/ \mathrm{ba} /$ syllable at one end and the perception of a/da/ syllable at the other end. The modification of the onset of the initial frequency transition (SIN2 and SIN3) accounted for the difference of place of articulation. The frequency at onset varied from $975 \mathrm{~Hz}$ to $1800 \mathrm{~Hz}$ in 3 equal steps of $275 \mathrm{~Hz}$ for SIN2 and from $1975 \mathrm{~Hz}$ to $3400 \mathrm{~Hz}$ in 3 equal steps of $475 \mathrm{~Hz}$ for SIN3. The frequencies at the end of SIN2 and SIN3 transition were set at $1300 \mathrm{~Hz}$ and $2500 \mathrm{~Hz}$. The stimuli were tagged according to their phoneme identity (i.e., depending on their predominant identification as $/ \mathrm{ba} /$ or $/ \mathrm{da} /$ ) and to the onset of SIN2: ba975, ba1250, da1525 and da1800. The lowest formant frequency (F1) at onset was $100 \mathrm{~Hz}$, and $750 \mathrm{~Hz}$ at end. The VOT was 60 $\mathrm{ms}$, and the whole vocalic period lasted $170 \mathrm{~ms}$ including a $40 \mathrm{~ms}$ period of all-frequency transition. Stimuli pairs consisted of pure sinewaves (with an ISI of $100 \mathrm{~ms}$ ); the allocated timùe for response was $1440 \mathrm{~ms}$, yielding an SOA of $2 \mathrm{~s}$. Pairs involved either the same stimulus (BA1/BA1; DA1/DA1; BA2/BA2 and DA2/DA2), "within-category" stimuli (i.e., pairs in which stimuli differed in acoustic terms but pertained to the same phonological 
category: BA1/BA2 and BA2/BA1; DA1/DA2 and DA2/DA1) or "between-category" stimuli (i.e., pairs in which stimuli differed in phonological terms, BA1/DA2 and DA2/BA1). Each experimental run was made of 72 pairs of stimuli pseudorandomly distributed among the three types of pairs, with 24 SAME (6BA1/BA1; 6DA1/DA1; 6BA2/BA2 and 6DA2/DA2), 24 WITHIN (6BA1/BA2; 6BA2/BA1; 6DA1/DA2 and 6DA2/DA1) and 24 BETWEEN (12BA1/DA2 and 12DA2/BA1) pairs.

Individuals with dyslexia and average readers were asked to produce identical/different responses by clicking on either the right or the left button of a PC mouse to pairs of auditory stimuli made of sinewave speech (/ba/ and /da/ syllables, (see Serniclaes et al., 2001, Dehaene-Lambertz et al., 2005 for details). The 'identical' responses were associated with either the right or the left mouse button in balanced subgroups of healthy and dyslexic individuals.

The PET procedure involved 8 sessions including 3 runs for 2 experimental tasks, interspersed with 2 rest runs without auditory stimulation. In the first 3 runs, the pure sinewave synthetic stimuli were used and subjects were told that they will perform an auditory task involving electronic sounds, avoiding any reference to language processing (SWacoustic or "AC" condition / acoustic mode). After these first 3 runs, subjects were debriefed and instructed that the stimuli were in fact synthetic syllables (SWspeech or "SP" condition / linguistic mode) and were trained to discriminate those among the pure sinewave synthetic stimuli which corresponded to either /ba/ versus /da/ syllable. For the sake of rapid training efficacy, subjects were trained with SAME and BETWEEN pairs, presented in six short sessions of twenty pairs. All subjects quickly reached a $75 \%$ of accurate judgment using these stimuli.

Subjects were asked to listen carefully and detect possible differences between the 72 stimuli pairs'. The PET experiment further engaged the second experimental conditions involving 
three runs involving pure sinewave synthetic stimuli like in the first three ones but keeping in mind they corresponded to syllables, SP. Before each experimental condition, a demonstration of twenty pairs of sounds (10 SAME and 10 BETWEEN) were presented to keep subjects familiar with the task.

The experimental condition involving the fundamental frequency (F0) described in our previous work (Dufor et al., 2007) was not considered as it really differed in terms of stimuli contents. This condition and training session containing these stimuli with F0 were always presented after debriefing so that participants could become familiar with the linguistic nature of stimuli before confronting them again with sinewave analogues.

Data analysis. The behavioural performance considered in the present study were individual accuracy scores (correct responses, CR) collected for the sinewave stimuli. Accuracy scores consisted of "identical" responses to SAME pairs, "different" responses to BETWEEN pairs and "different" responses for WITHIN pairs. It should be noted that for the WITHIN pair type the assignment of accuracy to "different" responses refers to differences in acoustic terms whereas, in consideration of categorical perception, one would expect "identical" responses to be the correct answers. Performance distribution for WITHIN pairs was preferred to that for SAME pairs as the former more likely reflects the effect of perceptual ambiguousness and the variability of performance across subjects.

Three individual scores were calculated in each subject. These CR scores are as follows:

$\mathrm{CR}(\mathrm{SAME})=$ (responses "identical" to SAME pairs / total number of SAME pairs).

$\mathrm{CR}($ WITHIN $)=$ (responses "different" to WITHIN pairs / total number of WITHIN pairs)

$\mathrm{CR}(\mathrm{BETWEEN})=($ responses "different" to BETWEEN pairs / total number of BETWEEN pairs) 
These scores were calculated for both the Speech condition (SP) and the Acoustic condition (AC) and then were subtracted making a delta score $(\Delta)$, as follows, $\Delta \mathrm{SAME}_{\mathrm{SP}-\mathrm{AC}}=\mathrm{CR}(\mathrm{SAME})_{\mathrm{SP}}-\mathrm{CR}(\mathrm{SAME})_{\mathrm{AC}}$ $\Delta$ WITHIN $_{\mathrm{SP}-\mathrm{AC}}=\mathrm{CR}(\mathrm{WITHIN})_{\mathrm{SP}}-\mathrm{CR}(\mathrm{WITHIN})_{\mathrm{AC}}$ $\triangle \mathrm{BETWEEN}_{\mathrm{SP}-\mathrm{AC}}=\mathrm{CR}(\mathrm{BETWEEN})_{\mathrm{SP}}-\mathrm{CR}(\mathrm{BETWEEN})_{\mathrm{AC}}$

Neuroimaging data were analyzed with SPM2. Images were realigned using the first scan as reference and then normalised into the standard space of the Montreal Neurological Institute template and smoothed with a 8-mm Gaussian filter. First, across condition activation contrasts were obtained in each subject (e.g., (Subject 1: $\left.\mathrm{CBF}_{\mathrm{SP}}>\mathrm{CBF}_{\mathrm{AC}}\right)$ ). Then within-group correlation contrasts were constructed (parametric threshold $\mathrm{P}<0.005, \mathrm{k}=30$ voxels) so that each subject's contrast $\left(\mathrm{CBF}_{\mathrm{SP}}-\mathrm{CBF}_{\mathrm{AC}}\right)(1 \ldots \mathrm{n})$ was associated with subject's score (e.g. $\left(\Delta\right.$ WITHIN $\left.\left._{\text {SP-AC }}\right)(1 \ldots \mathrm{n})\right)$. This statistical threshold was chosen to explore correlation effects in SPM2 and to present maps on 3D rendering of brain volumes (MRIcro ${ }^{\circledR}$ software). As this uncorrected threshold and parametric test can be too lenient for non normal data distribution, we used non parametric approach to test the validity of these findings. Therefore, we extracted and tested again all rCBF variations for each cluster peak against the performance's vectors in a non parametric Spearman correlation test with the Statistica $6^{\circledR}$ software $(\mathrm{p}=$ 0.001). Cluster which did not appear significantly activated at $\mathrm{p}<0.001$ after this non parametric correction were only considered as trends and not commented.

\section{Results}

Behavioural performances. 
From subjects' response scores to each type of pairs, we designed and compared vectors before entering them in the PET analysis. Table 1 gives the means and SDs of the delta scores $\left(\triangle\right.$ SAMESP-AC,$\triangle$ WITHIN $_{S P-A C}$, and $\triangle$ BETWEEN $\left._{\text {SP-AC }}\right)$ as well as the Spearman $\mathrm{r}$ correlations between these scores for each group (dyslexia and control). In both groups, the $\triangle \mathrm{SAME}_{\mathrm{SP}-\mathrm{AC}}$ scores were strongly correlated to $\triangle \mathrm{WITHIN}_{\mathrm{SP}-\mathrm{AC}}$ scores. However, the $\triangle$ BETWEEN $_{\text {SP-AC }}$ did not correlate neither with the $\triangle$ SAME $_{\text {SP-AC }}$ or $\Delta$ WITHIN $_{\text {SP-AC }}$ scores. Overall, subjects who responded more frequently "different" to WITHIN pairs in the SP vs. AC conditions were those who gave less "identical" responses to SAME pairs for the SP condition than for the AC condition. This pattern of performance suggests a lack of categorical perception in some subjects when facing ambiguous and artefactual stimuli; a trend which might be reinforced by the presence of WITHIN pairs in the stimulus set. These findings complement our previously reported results (Dufor et al., 2007) which were based on the contrast between AC and SP conditions and were dominated by the massive improvement of discrimination observed for BETWEEN pairs, this pattern of performance being clearly categorical for this type of stimuli. By contrast the response profile was less categorical for the WITHIN and SAME pairs.

The next section describes how changes in local brain activation between the AC and SP conditions correlate with changes in performance on WITHIN pairs across subjects. 
Correlation between PET results and performance in speech sound discrimination during the

\section{PET session}

Correlations between local $\mathrm{CBF}$ changes and ba/da discrimination changes between the 'Speech' (SP) and 'Acoustic' (AC) conditions were computed. Discrimination performance was assessed with the above mentioned $\Delta$ WITHIN $_{\text {SP-AC }}$ scores, i.e. the differences in correct discrimination of the within-category pairs between the AC and SP conditions. Regions in which significant between group differences in $\triangle \mathrm{CBF}-\triangle$ WITHIN correlations were found are reported in Table 2. Tests of correlations within each group, either dyslexic or healthy, are reported in Tables 4 and 5, respectively.

The between group comparison revealed three regions bearing significant differences in $\Delta$ CBF- $\Delta$ WITHIN non parametric Spearman rank correlations $(\mathrm{p}<0.001$, clusters numbered 1 to 3 in Figure 1). Cluster (1) was located in the left inferior frontal gyrus (BA6) and cluster (2) in the left insula spreading outwards to "Broca's area". The cluster (3) was localized in the right cingulate (BA24). In the first two clusters, the same region of the left frontal cortex showed criss-crossed effects between groups (Figure 1). In the healthy group, the observed correlation is such that the largest $\mathrm{rCBF}$ effects were observed in subjects who produced the largest increase of the rate of "same" responses to WITHIN pairs. Among healthy subjects, the scattergram (Figure 1) showed that only a subgroup of subjects (whom one may term 'best categorizers') tended to increase their categorical perception of WITHIN pairs. On the contrary, in the dyslexia group, the largest signals were seen in subjects who increased the rate of 'different' responses to WITHIN, therefore showing the largest sensitivity to acoustic, linguistically irrelevant cues. 
Unlike the former two clusters, cluster 3 (BA24) showed similar $\Delta$ CBF- $\Delta$ WITHIN relationship in both groups; however the slope of this positive correlation was steeper for the dyslexic group than for the healthy group.

Complementary analyses were conducted in order to test the significance of the $\triangle \mathrm{CBF}$ $\Delta$ WITHIN correlations within each group over the whole brain volume. We report here only the findings that are relevant to between-group effects at stake. In the healthy group, significant negative correlations were found in a large left-sided cluster encompassing BAs 22 and 6 (with two distinct maxima), and in the right BA24 region, the latter being not colocalized with cluster 3 described in the between-group comparison (Table 3). A trend was also observed in a cluster encompassing the left insular cortex (BA13) although its maximum peak was localized in BA47 (Table 3). In the dyslexia group, significant positive correlations were found in the left insula and BA44 regions, as well as in the right BA24 region (Table 4).

\section{Discussion}

In a previous analysis of the present data (Dufor et al., 2007), we focused on mean rCBF differences between conditions and groups and found a leftward shift of brain activity from acoustic to speech mode for control readers but not for dyslexic subjects although both groups learned to discriminate stimuli in a categorical way. In the present study, we looked for further differences in the neuronal correlates of categorical perception between individuals with dyslexia and typical readers. In this purpose, we examined individual differences in changes between perceptual modes and found that, in both groups, subjects differed more to each other in behavioural performance on within- than on between-category pairs. We 
therefore examined the relationship between changes in discrimination for within-category pairs and changes in $\mathrm{rCBF}$ across $\mathrm{AC}$ and SP conditions.

From a behavioural point of view, the discrimination data of our previous study (Dufor et al., 2007) showed a massive improvement of between-category discrimination in the SP vs. AC condition. However, categorical perception depends both on the discrimination of betweencategory pairs, the larger the more categorical, and on the discrimination of within-category pairs and same pairs, the lesser the more categorical. The present analyses showed that large variations across subjects existed between SP to AC changes in discrimination scores for within and same pairs and these changes were correlated together (Table 1). In each group, some subjects tended to display an enhanced categorical perception profile; indeed, these subjects did not discriminate differences in the "WITHIN" type of pairs while they kept responding correctly to the "SAME" type of pairs. On the contrary, some subjects tended to enhance both acoustic differences discrimination in "WITHIN" pairs and error rate on "SAME" type of pairs (i.e. reported differences in WITHIN and SAME pairs). Two competing perceptual modes, either a categorical mode or a mode based on acoustic differences in stimuli, seem to prevail in our two groups. In the acoustic mode, it might be that subjects focused on search for differences in stimuli therefore yielding a high rate of detection of acoustic differences in "WITHIN" pairs, even in the speech mode, and of fallacious detection of differences in "SAME" type of pairs. While this behavioural variability was present in both groups, examination of the PET data indicates different relationships with brain activity between dyslexic readers and controls.

Speech categorisation paradigm has already been use in fMRI studies. Our expectation was to find a significantly correlated region in the left inferior frontal cortex as this region was demonstrated to be sensitive to efficient categorical perception of standard speech in the healthy group while individuals with dyslexia showed decreased activity in this region (Ruff 
et al., 2002). Moreover, recent experiments demonstrated implications of the left inferior frontal cortex, insula and temporal cortex in perceptual categorisation processes using phonetic continuum (Binder et al., 2004, Blumstein et al., 2005, Liebenthal et al., 2005, Hutchison et al., 2008). Finally, in the healthy group only, other regions could be involved owing to functional relationships that likely exist during language tasks between the inferior frontal cortex and for instance the inferior parietal region in the left hemisphere (Horwitz et al., 1998).

Regions crucial to phoneme processing, located in BAs 6,13 , as well as portions of BA 24, exhibited significant differences in $\triangle \mathrm{CBF}-\triangle \mathrm{WITHIN}$ correlation between groups In the former two regions criss-crossed effects were observed between groups with negative correlation in the average readers and positive correlation in participants with dyslexia. Furthermore, in the same regions, within-group analyses showed clusters with similar significant correlations.

In average readers, we observed, activities in the left inferior lateral frontal regions that were correlated with phoneme categorization. Overall, these results are in accordance with the well-acknowledged, distributed neural system dealing with phonological processes and motor speech coding across the left perisylvian cortex in average right-handed subjects (Demonet et al., 2005b, Vigneau et al., 2006). More specifically, our results are in keeping with those of two studies (Blumstein et al., 2005, Hutchison et al., 2008). The first one showed that identification processes of within-stimuli in a healthy group elicited activation in this same region and co-varied with the phonetic distance between the current stimulus and subject's own prototypic category. The second study showed, in post-hoc analysis, that discrimination of stimuli straddling the phonemic boundary and near to it, $(15 \mathrm{~ms}$ VOT) recruited more 
activity in the left inferior frontal region (L-IFG) than more distant stimuli (30 ms VOT) that correspond to classical between-category pairs.;

In BA 6 region, a number of previous studies concerning phonological processes either from auditory or visual input have shown strong activity in the left inferior and middle frontal gyri and the supplementary motor area (SMA) that has been linked to inner speech production, even though in a covert modality ('inner speech') (Frith et al., 1991, Demonet et al., 1992, Paulesu et al., 1993, Price et al., 1994, Demonet et al., 2005a, Vigneau et al., 2006). Covertly producing speech may have taken place in our experiment as a strategy subjects used to confront the differences between the current stimuli and those occurring in the production of naturally produced syllables (which themselves refer to subject's own phonological prototypes or known syllables). In the set of stimuli used in this experiment, 'WITHIN' stimuli were acoustically equidistant between the categorical boundary and the extremes /BA/ (or /DA/) used in 'BETWEEN' pairs. After debriefing, when subjects had to rely on a linguistic mode: they likely tended to match stimuli with known, natural /BA/ and /DA/ syllables. Inner speech might therefore play an important role in (that case of) learning and yield 'identical' responses to WITHIN pairs since both members of the pair matched the same, covertly produced syllable.

With regard to effects in BA13/BA47, this portion of the left premotor cortex has been involved in motor programming of speech units (Wise et al., 1999); lesions localized in these regions tend to induce apraxia of speech (Dronkers, 1996, Hillis et al., 2004).

Interestingly, dyslexic subjects who had close-to-normal categorical performances showed the lowest activity in these left premotor areas; this result suggests that best performers in the dyslexia group would not resort to motor coding of phonological units. Whereas the left posterior inferior frontal cortex is normally involved in phonological processing, our findings suggest that some subregions did not subserve phoneme categorisation in dyslexic subjects, 
and are instead sensitive to linguistically irrelevant, acoustic variants of the same phonemic category. In the most impaired of our dyslexic subjects, these areas would therefore participate in an aberrant, non categorical way of speech coding. Serniclaes and colleagues (Serniclaes et al., 2004) proposed that speech processing in mother tongue in dyslexic subjects may be affected by the persistence of perceptual boundaries between allophones which would challenge categorisation based on the phonemic categories. In the early childhood exposition to mother tongue is supposed to reinforce the relevant phoneme categories, while other phonetic contrasts (yielding allophones) should be cancelled out (Kuhl et al., 1997). The present results, while substantiating this theoretical account, suggest however that this phenomenon is limited to the poorest categorizers in adult dyslexic subjects.

In the right BA24, different effects were observed in either group.

In the within-group analysis, a negative correlation was found for the healthy group in this region that might receive several interpretations. Effect close to the boundaries of the SMA could be attributed to the engagement of the phonology-related motor system (as mentioned above about covert speech production).

Another way to account for the engagement of the anterior cingulate in the subjects who most efficiently categorized stimuli, relates to decisional processes that have to take place to differentiate conflicting responses, i.e. acoustic-based discrimination versus language-based assimilation of the components of 'WITHIN' pairs. Although, the region of the anterior cingulate we observed is fairly far from the region in the left hemisphere measured in the Blumstein's study (Blumstein et al., 2005), their cluster extended to the right hemisphere and the comparison of our ' $\mathrm{z}$ ' coordinates; $\mathrm{z}=46 \mathrm{~mm}$ for the healthy group with those extracted from their study $\mathrm{z}=45$ show an important overlap. Blumstein et al. did invoke executive processes to account for these results. Further, we reviewed 172 other coordinates from 
studies including notably (Barch et al., 2001), and compare the observed coordinates in our own results. This complementary analysis showed that the cluster found in the healthy group for the within-group analysis, was included in a group of coordinates linked to production of adequate motor responses in forced-choice or go/no go tasks (Zatorre et al., 1992, Paulesu et al., 1993, Paus et al., 1993, Kawashima et al., 1996, Jueptner et al., 1997, Derbyshire et al., 1998, Samuel et al., 1998, Barch et al., 2001, Kiehl et al., 2001, Todd and Botteron, 2001).

Within-group analysis in the dyslexia group showed two cluster positively correlated with WITHIN pairs discrimination that were nearly overlapping with cingulate regions implicated in conflict monitoring (Phelps et al., 1997, Barch et al., 2001, Nelson et al., 2003) for the first one $(\mathrm{x}, \mathrm{y}, \mathrm{z}=4,18,27)$, and close to activation foci associated with incongruent responses for the second one (Bench et al., 1993, George, 1994, Barch et al., 2001) (x,y,z = 4, -17, 34), a finding that may correspond to uncertainty in dyslexic subjects' responses who might have hesitated between categorical and acoustic-based responses.

Finally, the positively correlated cluster in the right BA24 revealed by the between-group analysis was significantly steeper in the dyslexic group although the trend was similar in the healthy group. This cluster was very close to those reported in the literature as reflecting mismatch between instruction given to and responses provided by subjects especially in Stroop experiments (Bench et al., 1993, George, 1994, Barch et al., 2001). It might stand for a cortical response that may reflect error signalling during task performance. This function therefore appears especially engaged in the dyslexic subjects for whom the task was particularly challenging, while a weaker, non significant but similar trend existed in the healthy group. 
Overall the main findings that concern signal changes in the left BA6, lend further support to the hypothesis of allophonic perception in dyslexia. Indeed one might speculate that these regions harbour neural populations that can code for phoneme boundaries from different languages (Golestani and Zatorre, 2004, Golestani and Pallier, 2007) and that may subserve the initial ability of infants to discriminate even between foreign phonological contrasts (Werker and Tees, 1984, Dehaene-Lambertz et al., 2002, Burnham, 2003, Dehaene-Lambertz et al., 2006a, Dehaene-Lambertz et al., 2006b). Our findings in control readers suggest that subjects able to categorize at best can optimize categorical perception thanks enhanced motor coding of speech signal in the inferior part of the left BA6. The enhancement of rCBF signal in this region was associated with increased sensitivity to within-category phonetic variations in dyslexic subjects. This result suggests the pathological persistence of phoneme boundaries that should normally have disappeared over mother tongue learning in early childhood. Statistical regularities in speech signals resulting from the phonological organization of a given language makes irrelevant previously perceived phonemic oppositions; phonetic contrasts irrelevant for the mother tongue should therefore generate much less neural activity in the left inferior premotor areas than those typical of this language.

Further studies are needed to address directly whether (i) motor coding of speech representations are impaired in dyslexia, (ii) a sub-group of dyslexic subjects resort to persistent allophonic representations instead of mother-tongue phoneme categories to process speech, (iii) what are the brain underpinnings of these dysfunctions. 


\section{Acknowledgement:}

This study was supported by the French 'Programme Interdisciplinaire, Cognition et Traitement de l'Information (Centre National de la Recherche Scientifique), CT101-53' headed by Liliane Sprenger-Charolles and Willy Serniclaes and a personal grant (OD) from the "Fondation pour la Recherche Médicale" FRM. Thanks to the technical staff of the Toulouse PET centre, thanks to Marie-Pierre Dupont, to Michèle Charnay (President of the APEDYS-HG) and Annick Celsis for their help in recruiting dyslexic participants. 


\section{References}

Barch, D. M., Braver, T. S., Akbudak, E., Conturo, T., Ollinger, J. and Snyder, A., 2001. Anterior cingulate cortex and response conflict: effects of response modality and processing domain. Cereb Cortex. 11, 837-848.

Bench, C. J., Frith, C. D., Grasby, P. M., Friston, K. J., Paulesu, E., Frackowiak, R. S. and Dolan, R. J., 1993. Investigations of the functional anatomy of attention using the Stroop test. Neuropsychologia. 31, 907-922.

Binder, J. R., Liebenthal, E., Possing, E. T., Medler, D. A. and Ward, B. D., 2004. Neural correlates of sensory and decision processes in auditory object identification. Nat Neurosci. 7, 295-301.

Blumstein, S. E., Myers, E. B. and Rissman, J., 2005. The perception of voice onset time: an fMRI investigation of phonetic category structure. J Cogn Neurosci. 17, 1353-1366.

Bogliotti, C., Serniclaes, W., Messaoud-Galusi, S. and Sprenger-Charolles, L., 2008. Discrimination of speech sounds by children with dyslexia: Comparisons with chronological age and reading level controls. J Exp Child Psychol.

Brandt, J. and Rosen, J. J., 1980. Auditory phonemic perception in dyslexia: categorical identification and discrimination of stop consonants. Brain Lang. 9, 324-337.

Burnham, D., 2003. Language specific speech perception and the onset of reading. Reading and Writing. 16, 573-609.

Dehaene-Lambertz, G., Dehaene, S. and Hertz-Pannier, L., 2002. Functional neuroimaging of speech perception in infants. Science. 298, 2013-2015.

Dehaene-Lambertz, G., Hertz-Pannier, L. and Dubois, J., 2006a. Nature and nurture in language acquisition: anatomical and functional brain-imaging studies in infants. Trends Neurosci. 29, 367-373.

Dehaene-Lambertz, G., Hertz-Pannier, L., Dubois, J., Meriaux, S., Roche, A., Sigman, M. and Dehaene, S., 2006b. Functional organization of perisylvian activation during presentation of sentences in preverbal infants. Proc Natl Acad Sci U S A. 103, 1424014245.

Dehaene-Lambertz, G., Pallier, C., Serniclaes, W., Sprenger-Charolles, L., Jobert, A. and Dehaene, S., 2005. Neural correlates of switching from auditory to speech perception. Neuroimage. 24, 21-33.

Demonet, J. F., Chollet, F., Ramsay, S., Cardebat, D., Nespoulous, J. L., Wise, R., Rascol, A. and Frackowiak, R., 1992. The anatomy of phonological and semantic processing in normal subjects. Brain. 115 ( Pt 6), 1753-1768.

Demonet, J. F., Pernet, C., Kouider, S. and Musso, M., 2005a. The dynamics of languagerelated brain images. Neurocase. 11, 148-150.

Demonet, J. F., Taylor, M. J. and Chaix, Y., 2004. Developmental dyslexia. Lancet. 363, 1451-1460.

Demonet, J. F., Thierry, G. and Cardebat, D., 2005b. Renewal of the neurophysiology of language: functional neuroimaging. Physiol Rev. 85, 49-95.

Derbyshire, S. W., Vogt, B. A. and Jones, A. K., 1998. Pain and Stroop interference tasks activate separate processing modules in anterior cingulate cortex. Exp Brain Res. 118, $52-60$

Desai, R., Liebenthal, E., Waldron, E. and Binder, J. R., 2008. Left Posterior Temporal Regions are Sensitive to Auditory Categorization. J Cogn Neurosci. 20, 1174-1188.

Dronkers, N. F., 1996. A new brain region for coordinating speech articulation. Nature. 384, 159-161. 
Dufor, O., Serniclaes, W., Sprenger-Charolles, L. and Demonet, J. F., 2007. Top-down processes during auditory phoneme categorization in dyslexia: a PET study. Neuroimage. 34, 1692-1707.

Frith, C. D., Friston, K. J., Liddle, P. F. and Frackowiak, R. S., 1991. A PET study of word finding. Neuropsychologia. 29, 1137-1148.

George, M. S., Ketter T.A., Parekh PI, Rosinsky N, Ring H, Casey BJ, Trimble MR, Horwitz B, Herscowitch P, Post RM, 1994. Regional brain activity when selecting a response despite interference: an O-15 PET study of the Stroop and an emotional Stroop. Hum Brain Mapp. 1, 55-63.

Giraud, K., Demonet, J. F., Habib, M., Marquis, P., Chauvel, P. and Liegeois-Chauvel, C., 2005. Auditory evoked potential patterns to voiced and voiceless speech sounds in adult developmental dyslexics with persistent deficits. Cereb Cortex. 15, 1524-1534.

Giraud K, Trébuchon-DaFonseca A, Démonet JF, Habib M, Liégeois-Chauvel C. Clin Neurophysiol. 2008 Jul;119(7):1652-63).

Golestani, N. and Pallier, C., 2007. Anatomical correlates of foreign speech sound production. Cereb Cortex. 17, 929-934.

Golestani, N. and Zatorre, R. J., 2004. Learning new sounds of speech: reallocation of neural substrates. Neuroimage. 21, 494-506.

Hillis, A. E., Work, M., Barker, P. B., Jacobs, M. A., Breese, E. L. and Maurer, K., 2004. Reexamining the brain regions crucial for orchestrating speech articulation. Brain. 127, 1479-1487.

Horwitz, B., Rumsey, J. M. and Donohue, B. C., 1998. Functional connectivity of the angular gyrus in normal reading and dyslexia. Proc Natl Acad Sci U S A. 95, 8939-8944.

Hutchison, E. R., Blumstein, S. E. and Myers, E. B., 2008. An event-related fMRI investigation of voice-onset time discrimination. Neuroimage. 40, 342-352.

Jueptner, M., Frith, C. D., Brooks, D. J., Frackowiak, R. S. and Passingham, R. E., 1997. Anatomy of motor learning. II. Subcortical structures and learning by trial and error. J Neurophysiol. 77, 1325-1337.

Kawashima, R., Satoh, K., Itoh, H., Ono, S., Furumoto, S., Gotoh, R., Koyama, M., Yoshioka, S., Takahashi, T., Takahashi, K., Yanagisawa, T. and Fukuda, H., 1996. Functional anatomy of GO/NO-GO discrimination and response selection--a PET study in man. Brain Res. 728, 79-89.

Kiehl, K. A., Laurens, K. R., Duty, T. L., Forster, B. B. and Liddle, P. F., 2001. Neural sources involved in auditory target detection and novelty processing: an event-related fMRI study. Psychophysiology. 38, 133-142.

Kuhl, P. K., Andruski, J. E., Chistovich, I. A., Chistovich, L. A., Kozhevnikova, E. V., Ryskina, V. L., Stolyarova, E. I., Sundberg, U. and Lacerda, F., 1997. Cross-language analysis of phonetic units in language addressed to infants. Science. 277, 684-686.

Liberman, A. M., Harris, K. S., Hoffman, H. S. and Griffith, B. C., 1957. The discrimination of speech sounds within and across phoneme boundaries. J Exp Psychol. 54, 358-368.

Liebenthal, E., Binder, J. R., Spitzer, S. M., Possing, E. T. and Medler, D. A., 2005. Neural substrates of phonemic perception. Cereb Cortex. 15, 1621-1631.

Nelson, J. K., Reuter-Lorenz, P. A., Sylvester, C. Y., Jonides, J. and Smith, E. E., 2003. Dissociable neural mechanisms underlying response-based and familiarity-based conflict in working memory. Proc Natl Acad Sci U S A. 100, 11171-11175.

Oldfield, R. C., 1971. The assessment and analysis of handedness: the Edinburgh inventory. Neuropsychologia. 9, 97-113.

Paulesu, E., Demonet, J. F., Fazio, F., McCrory, E., Chanoine, V., Brunswick, N., Cappa, S. F., Cossu, G., Habib, M., Frith, C. D. and Frith, U., 2001. Dyslexia: cultural diversity and biological unity. Science. 291, 2165-2167. 
Paulesu, E., Frith, C. D. and Frackowiak, R. S., 1993. The neural correlates of the verbal component of working memory. Nature. 362, 342-345.

Paus, T., Petrides, M., Evans, A. C. and Meyer, E., 1993. Role of the human anterior cingulate cortex in the control of oculomotor, manual, and speech responses: a positron emission tomography study. J Neurophysiol. 70, 453-469.

Pernet, C. A., J. Paulesu, E. Demonet, J.F., 2008. When All Hypotheses are Right:A Multifocal Account of Dyslexia. Human Brain Mapping. in press.

Phelps, E. A., Hyder, F., Blamire, A. M. and Shulman, R. G., 1997. FMRI of the prefrontal cortex during overt verbal fluency. Neuroreport. 8, 561-565.

Price, C. J., Wise, R. J., Watson, J. D., Patterson, K., Howard, D. and Frackowiak, R. S., 1994. Brain activity during reading. The effects of exposure duration and task. Brain. 117 ( Pt 6), 1255-1269.

Ramus, F., Rosen, S., Dakin, S. C., Day, B. L., Castellote, J. M., White, S. and Frith, U., 2003. Theories of developmental dyslexia: insights from a multiple case study of dyslexic adults. Brain. 126, 841-865.

Rosen, S., 2003. Auditory processing in dyslexia and specific language impairment: Is there a deficit? What is its nature? Does it explain anything? . Journal of Phonetics. 31, 509527.

Ruff, S., Cardebat, D., Marie, N. and Demonet, J. F., 2002. Enhanced response of the left frontal cortex to slowed down speech in dyslexia: an fMRI study. Neuroreport. 13, 1285-1289.

Ruff, S., Marie, N., Celsis, P., Cardebat, D. and Demonet, J. F., 2003. Neural substrates of impaired categorical perception of phonemes in adult dyslexics: an fMRI study. Brain Cogn. 53, 331-334.

Samuel, M., Williams, S. C., Leigh, P. N., Simmons, A., Chakraborti, S., Andrew, C. M., Friston, K. J., Goldstein, L. H. and Brooks, D. J., 1998. Exploring the temporal nature of hemodynamic responses of cortical motor areas using functional MRI. Neurology. $51,1567-1575$.

Serniclaes, W. and Geng, C., accepted. Cross-Linguistic trends in the perception of place of articulation in stop consonants: A comparison between Hungarian and French. In Chitoran, I, Coupé, C, Marsico, E, \& Pellegrino, F "Approaches to phonological complexity" (Mouton de Gruyter).

Serniclaes, W., Sprenger-Charolles, L., Carre, R. and Demonet, J. F., 2001. Perceptual discrimination of speech sounds in developmental dyslexia. J Speech Lang Hear Res. 44, 384-399.

Serniclaes, W., Van Heghe, S., Mousty, P., Carre, R. and Sprenger-Charolles, L., 2004. Allophonic mode of speech perception in dyslexia. J Exp Child Psychol. 87, 336-361.

Silani, G., Frith, U., Demonet, J. F., Fazio, F., Perani, D., Price, C., Frith, C. D. and Paulesu, E., 2005. Brain abnormalities underlying altered activation in dyslexia: a voxel based morphometry study. Brain. 128, 2453-2461.

Sprenger-Charolles, L., Colé, P., Serniclaes, W., 2006. Reading acquisition and developmental dyslexia. New York: Psychology Press (Developmental Essays).

Stein, J. and Walsh, V., 1997. To see but not to read; the magnocellular theory of dyslexia. Trends Neurosci. 20, 147-152.

Tallal, P. and Piercy, M., 1973. Defects of non-verbal auditory perception in children with developmental aphasia. Nature. 241, 468-469.

Todd, R. D. and Botteron, K. N., 2001. Is attention-deficit/hyperactivity disorder an energy deficiency syndrome? Biol Psychiatry. 50, 151-158. 
Vigneau, M., Beaucousin, V., Herve, P. Y., Duffau, H., Crivello, F., Houde, O., Mazoyer, B. and Tzourio-Mazoyer, N., 2006. Meta-analyzing left hemisphere language areas: phonology, semantics, and sentence processing. Neuroimage. 30, 1414-1432.

Werker, J. F. and Tees, R. C., 1984. Phonemic and phonetic factors in adult cross-language speech perception. J Acoust Soc Am. 75, 1866-1878.

Wise, R. J., Greene, J., Buchel, C. and Scott, S. K., 1999. Brain regions involved in articulation. Lancet. 353, 1057-1061.

Zatorre, R. J., Evans, A. C., Meyer, E. and Gjedde, A., 1992. Lateralization of phonetic and pitch discrimination in speech processing. Science. 256, 846-849.

Tables \& Legends.

Performance on the speech sound discrimination task during the PET session

Table 1. Means and Standard deviations of the delta scores $\left(\Delta \mathrm{SAME}_{\mathrm{SP}-\mathrm{AC}}, \Delta \mathrm{WITHIN}_{\mathrm{SP}-\mathrm{AC}}\right.$, and $\triangle$ BETWEEN $\left._{\mathrm{SP}-\mathrm{AC}}\right)$ as well as the correlations between these scores for each group (control and dylexia).

\begin{tabular}{|c|c|c|c|c|c|}
\hline 1 & & \multicolumn{2}{|c|}{ control $(n=16)$} & \multicolumn{2}{|c|}{ dyslexia $(n=14)$} \\
\hline$\triangle$ SAME $_{\text {SP-AC }}$ & Mean \& SD & -0.166 & 0.235 & -0.068 & 0.203 \\
\hline$\Delta$ WITHIN $_{\text {SP-AC }}$ & Mean \& SD & 0.266 & 0.213 & 0.161 & 0.270 \\
\hline$\triangle$ BETWEEN $_{\text {SP-AC }}$ & Mean \& SD & 0.603 & 0.282 & 0.603 & 0.205 \\
\hline $\begin{array}{l}\Delta \text { SAME }_{S P-A C} \& \\
\Delta \text { WITHIN }_{\text {SP-AC }}\end{array}$ & $\begin{array}{l}\text { Spearman r } \\
\text { correlations } \\
\& \mathrm{p} \text { value }\end{array}$ & \multicolumn{2}{|c|}{$r=-0.62 p=0.009$} & \multicolumn{2}{|c|}{$r=-0.90 p<.0001$} \\
\hline $\begin{array}{l}\Delta \text { WITHIN }_{\text {SP-AC \& }} \\
\Delta \text { BETWEEN }_{\text {SP-AC }}\end{array}$ & $\begin{array}{c}\text { Spearman } \mathrm{r} \\
\text { correlations } \\
\& \mathrm{p}\end{array}$ & \multicolumn{2}{|c|}{$\mathrm{r}=0.11 \mathrm{p}=0.68$} & \multicolumn{2}{|c|}{$\mathrm{r}=0.14 \mathrm{p}=0.62$} \\
\hline
\end{tabular}




\begin{tabular}{|c|c|c|c|}
\hline $\begin{array}{c}\Delta \text { BETWEEN } \\
\text { SP-AC \& }\end{array}$ & $\begin{array}{c}\text { Spearman } \mathrm{r} \\
\text { correlations } \\
\text { \&AME }\end{array}$ & $\mathrm{r}=-0.01 \mathrm{p}=0.96$ & $\mathrm{r}=-0.08 \mathrm{p}=0.77$ \\
\hline
\end{tabular}

Figure 1: Brain regions showing significant variations between the two groups in correlated cerebral blood flows between SP and AC conditions with changes in performances for the $\Delta(\text { WITHIN })_{S P-A C}$ Scores. Clusters where correlations appear strongly different between groups are marked with an asterisk and numbered. CBF changes of each cluster peak are presented in the corresponding numbered graphic. (Control group in black and Dyslexic group in red). 'NIH Colours' on standardized brain $3 D$ renders show between group differences at $p=0.005$ (SPM uncorrected threshold).

Table 2: Significant differences between groups for correlation between $\Delta(\text { WITHIN })_{\mathrm{SP}-\mathrm{AC}}$ and $\Delta(\mathrm{CBF})_{\mathrm{SP}-\mathrm{AC}}$ contrast. Nota: we refer sometimes to BA13 as mentioned by the Talairach deamon $(\mathrm{C}$ software although BA13 was not described in humans but in primates.

\begin{tabular}{|c|c|c|c|c|c|c|c|c|c|c|}
\hline \multicolumn{11}{|c|}{ Differences between the two groups for the $\Delta(\mathrm{WITHIN})_{\mathrm{SP}-\mathrm{AC}}$ and $\Delta(\mathrm{CBF})_{\mathrm{SP}-\mathrm{AC}}$ contrast. } \\
\hline \multirow{2}{*}{ Hemisphere } & \multirow{2}{*}{ Area } & \multirow{2}{*}{$\begin{array}{l}\text { Brodmann } \\
\text { area }\end{array}$} & \multicolumn{3}{|c|}{ Talairach coordinates } & \multirow{2}{*}{$\begin{array}{r}\text { Voxel } \\
\text { extent }\end{array}$} & \multicolumn{2}{|c|}{$\begin{array}{c}\text { Spearman } \\
\text { r rank value }\end{array}$} & \multirow{2}{*}{$\begin{array}{c}\text { Voxel-level P } \\
\text { value } \\
\text { (uncorrected) }\end{array}$} & \multirow{2}{*}{$Z$ value } \\
\hline & & & $\mathbf{x}$ & $\mathbf{y}$ & $\mathbf{z}$ & & dyslexics & controls & & \\
\hline \multirow{2}{*}{ LEFT } & Inferior frontal gyrus & BA6 & -52 & 3 & 12 & 32 & $0.83^{*}$ & $-0.70 \mathrm{~ns}$ & 0.000 & 3.44 \\
\hline & Insula & (BA13) & -41 & 14 & -1 & 57 & $0.78^{*}$ & $-0.60 \mathrm{~ns}$ & 0.001 & 3.17 \\
\hline RIGHT & Cingulate gyrus & BA24 & 4 & -13 & 34 & 19 & $0.81^{*}$ & $0.36 \mathrm{~ns}$ & 0.000 & 3.48 \\
\hline
\end{tabular}

Table 3: Negative correlations between $\triangle \mathrm{WITHIN}_{\mathrm{SP}-\mathrm{AC}}$ and $\triangle \mathrm{CBF}$ SP-AC in Control readers near the regions where between-group differences in correlations were found. 


\begin{tabular}{|c|c|c|c|c|c|c|c|c|c|c|}
\hline \multicolumn{11}{|c|}{ Negative correlation between $\Delta(\text { WITHIN })_{\text {SP-AC }}$ and $\Delta(\mathrm{CBF})_{\text {SP-AC }}$ contrast in Control readers. } \\
\hline \multirow[t]{2}{*}{ Hemisphere } & \multirow{2}{*}{ Area } & \multirow{2}{*}{$\begin{array}{l}\text { Brodmann } \\
\text { area }\end{array}$} & \multicolumn{3}{|c|}{ Talairach coordinates } & \multirow{2}{*}{$\begin{array}{l}\text { Voxel } \\
\text { extent }\end{array}$} & \multirow{2}{*}{$\begin{array}{c}\text { Voxel-level P } \\
\text { value } \\
\text { (uncorrected) }\end{array}$} & \multirow{2}{*}{$\begin{array}{l}\text { Spearman } \\
\text { r rank value }\end{array}$} & \multirow{2}{*}{$\begin{array}{l}\text { Significance at } \\
p<0.001 \text { in the } \\
\text { Spearman non } \\
\text { parametric test }\end{array}$} & \multirow{2}{*}{$Z$ value } \\
\hline & & & $\mathbf{x}$ & $\mathbf{y}$ & $\mathbf{z}$ & & & & & \\
\hline \multirow[t]{2}{*}{ LEFT } & $\begin{array}{c}\text { Superior } \\
\text { temporal } \\
\text { gyrus / } \\
\text { Precentral } \\
\text { gyrus } \\
\end{array}$ & BA22/6 & $\begin{array}{l}-54 \\
-54\end{array}$ & $\begin{array}{c}-13 \\
1\end{array}$ & $\begin{array}{c}6 \\
12\end{array}$ & 152 & $\begin{array}{l}0.000 \\
0.001\end{array}$ & $\begin{array}{l}-0.68 \\
\mathbf{- 0 . 8 1}\end{array}$ & $\begin{array}{l}0.003 \mathrm{~ns} \\
\mathbf{0 . 0 0 0} *\end{array}$ & $\begin{array}{l}3.70 \\
\mathbf{3 . 1 7}\end{array}$ \\
\hline & $\begin{array}{l}\text { Inferior frontal } \\
\text { gyrus }\end{array}$ & BA47 & -38 & 14 & -14 & 77 & 0.002 & -0.56 & $0.021 \mathrm{~ns}$ & 2.84 \\
\hline RIGHT & Cingulate gyrus & BA24 & 8 & 6 & 46 & 74 & 0.001 & -0.78 & $0.000 *$ & 3.25 \\
\hline
\end{tabular}

Table 4: Positive correlations between $\Delta \mathrm{WITHIN}_{\mathrm{SP}-\mathrm{AC}}$ and $\triangle \mathrm{CBF}$ SP-AC in Dyslexics near the regions where between-group differences in correlations were found. Nota: we refer sometimes to BA13 as mentioned by the Talairach deamon(C) software although BA13 was not described in humans but in primates.

\begin{tabular}{|c|c|c|c|c|c|c|c|c|c|c|}
\hline \multicolumn{11}{|c|}{ Positive correlation between $\Delta(\mathrm{WITHIN})_{\mathrm{SP}-\mathrm{AC}} \underline{\text { and }} \Delta(\mathrm{CBF})_{\mathrm{SP}-\mathrm{AC}}$ contrast in Dyslexic readers. } \\
\hline \multirow{2}{*}{ Hemisphere } & \multirow{2}{*}{ Area } & \multirow{2}{*}{$\begin{array}{l}\text { Brodmann } \\
\text { area }\end{array}$} & \multicolumn{3}{|c|}{ Talairach coordinates } & \multirow{2}{*}{$\begin{array}{l}\text { Voxel } \\
\text { extent }\end{array}$} & \multirow{2}{*}{$\begin{array}{c}\text { Voxel- } \\
\text { level P } \\
\text { value } \\
\text { (uncorre } \\
\text { cted) } \\
\end{array}$} & \multirow{2}{*}{$\begin{array}{l}\text { Spearman } \\
\text { r rank value }\end{array}$} & \multirow{2}{*}{$\begin{array}{l}\text { Significance at } \\
p<0.001 \text { in the } \\
\text { spearman non } \\
\text { parametric test }\end{array}$} & \multirow{2}{*}{$Z$ value } \\
\hline & & & & $\mathbf{y}$ & $\mathbf{z}$ & & & & & \\
\hline \multirow{3}{*}{ LEFT } & \begin{tabular}{c|c}
$\begin{array}{c}\text { Inferior frontal } \\
\text { gyrus }\end{array}$ \\
\end{tabular} & BA44/6 & -52 & 4 & 16 & 128 & 0.000 & 0.89 & 0.000 * & 4.65 \\
\hline & \begin{tabular}{c|c|} 
Superior \\
temporal gyrus
\end{tabular} & $\begin{array}{c}\text { Very posterior } \\
\text { part (BA13) }\end{array}$ & -41 & -44 & 17 & 46 & 0.001 & 0.80 & 0.000 * & 3.27 \\
\hline & Insula & (BA13) & -45 & 6 & -3 & 251 & 0.001 & 0.72 & $0.003 \mathrm{~ns}$ & 3.19 \\
\hline RIGHT & Cingulate gyrus & BA24 & $\begin{array}{l}4 \\
4\end{array}$ & $\begin{array}{c}18 \\
-17\end{array}$ & $\begin{array}{l}27 \\
34\end{array}$ & $\begin{array}{l}42 \\
33\end{array}$ & $\begin{array}{l}0.000 \\
0.000\end{array}$ & $\begin{array}{l}0.92 \\
0.81\end{array}$ & $\begin{array}{l}0.000 * \\
0.000\end{array}$ & $\begin{array}{l}3.68 \\
3.33\end{array}$ \\
\hline
\end{tabular}



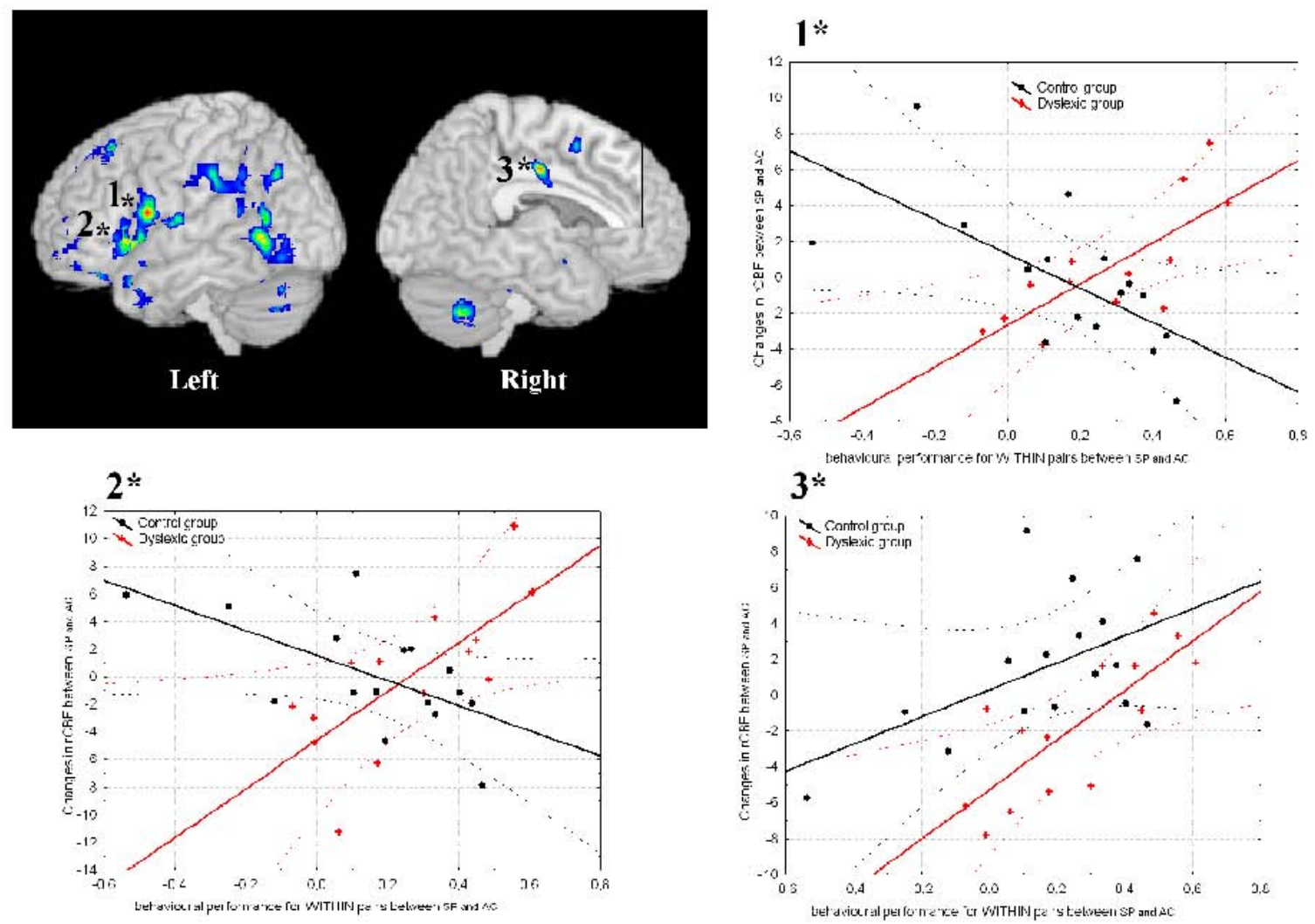